EXTENDED REPORT

\title{
Characterisation of the advanced glycation endproduct receptor complex in the retinal pigment epithelium
}

\author{
S McFarlane, J V Glenn, A M Lichanska, D A C Simpson, A W Stitt
}

Br J Ophthalmol 2005;89:107-112. doi: 10.1136/bjo.2004.045914

See end of article for authors' affiliations

Correspondence to: Professor A Stitt, Ophthalmology \& Vision Science, The Queen's University of Belfast, Institute of Clinical Science, Royal Victoria Hospital. Belfast BT1 2 6BA, UK; a.stitt@qub.ac.uk

Accepted for publication 16 April 2004

\begin{abstract}
Aims: Advanced glycation endproducts (AGEs) accumulate with ageing and may have a significant impact on age related dysfunction of the retinal pigment epithelium (RPE). Many of the cellular effects of AGEs in other cell types are mediated through AGE binding proteins. The aim of this study was to characterise the AGE receptor complex in RPE cells in vitro and to focus on the role of the R3 component (galectin-3) as the primary effector of the complex.

Methods: Primary cultures of bovine RPE cells and the human D407 RPE cell line were exposed to AGE modified albumin. Receptor expression was determined using mRNA analysis by quantitative real time RT-PCR and protein characterisation by western blotting. Immunocytochemical analysis examined the cellular localisation of the various components of the AGE receptor complex. The role of the galectin-3 receptor component was examined by transfection and overexpression using the D407 cell line and analysis of soluble AGE-R3 by ELISA.

Results: All three components of the AGE receptor complex were expressed by bovine and human RPE cells. AGE exposure upregulated two components of the receptor complex and also induced significant RPE expression of VEGF mRNA $(p<0.05)$. RPE D407 cells stably transfected to overexpress galectin-3 showed less VEGF induction. In non-transfected RPE which were exposed to AGEs, there was less soluble galectin-3 protein released into the medium $(p<0.05)$, a response that was not evident in transfected cells. Conclusion: A conserved AGE receptor complex is evident in primary cultures of bovine RPE cells and also in a human cell line. These cells show a pathological response to AGE exposure, an effect which appears to be modulated by the galectin-3 component of the receptor complex.
\end{abstract}

D uring ageing the retinal pigment epithelium/Bruch's membrane axis is known to undergo significant pathogenic changes. ${ }^{12}$ Indeed, progressive dysfunctional change in these retinal pigment epithelial (RPE) cells is thought to play a key role in the pathogenesis of age related macular degeneration (AMD) with age standing as the major, established risk factor for this disease. One of the characteristics of ageing is accumulation of advanced glycation endproducts (AGEs). These adducts have been pathogenically linked to several age related disorders and degenerative diseases including atherosclerosis, Alzheimer's disease, male erectile dysfunction, cataract formation, osteoarthritis, and pulmonary fibrosis. ${ }^{3}$ The pathogenic role of AGEs in age related disorders remains uncertain, as is the role of specific AGE receptors. This diverse array of proteins serve an important modulatory role in the binding, uptake, and degradation of AGE modified proteins in many cell types. ${ }^{4}$ In addition, they can also mediate many pathophysiological cell responses, such as the release of cytokines, increased expression of growth factors, or upregulation of extracellular matrix component proteins, or serve to remove them from the circulation/extracellular medium and/or illicit a range of dysfunctional responses in cells. It is known that AGEs accumulate and colocalise with their receptors in a wide variety of tissues. $^{45}$

Several AGE receptors and AGE binding proteins have been identified including the receptor for AGEs (RAGE), oligosaccharyl transferase-48 (AGE-R1), 80K-H (AGE-R2), and galectin-3 (AGE-R3). ${ }^{6}$ These proteins are believed to form a functional complex on the plasma membrane, although the mechanism by which they associate and modulate their effects is not completely understood. It is thought that AGE$\mathrm{Rl}$ is mainly involved in binding and endocytosis of AGE modified proteins, ${ }^{67}$ whereas the AGE-R2 and galectin-3 components are involved in AGE ligand binding. ${ }^{8-11}$
Advanced glycation endproducts have been shown to influence the behaviour of RPE cells in vitro. For example RPE cells have been shown to increase expression of platelet derived growth factor B (PDGF-B), ${ }^{12}$ and the potent angiogenic growth factor, vascular endothelial growth factor $(\mathrm{VEGF})^{13}$ in response to AGEs. Receptors for AGEs are expressed on a wide variety of cell types, including vascular endothelial cells, ${ }^{6814}$ macrophages, ${ }^{15}$ renal podocytes, ${ }^{16}$ vascular smooth muscle cells, ${ }^{17}$ microglia/astrocytes, ${ }^{18}$ and monocytes. ${ }^{19}$ However, the occurrence of such receptors in RPE has not been investigated. Therefore it is important to establish if these proteins are expressed by the RPE, because binding to AGE ligands and age related accumulation of AGE modified proteins could have important pathophysiological consequences for RPE function.

\section{MATERIALS AND METHODS \\ Cell culture}

Retinal pigment epithelial cells were isolated from bovine eyes using a previously published method.$^{20}$ Bovine RPE cells were maintained in MEM (Invitrogen) supplemented with $10 \%$ foetal calf serum, $100 \mathrm{U} / \mathrm{ml}$ penicillin, $100 \mu \mathrm{g} / \mathrm{ml}$ streptomycin, $1 \mathrm{mM} \mathrm{L-glutamine,} \mathrm{and} 2.5 \mu \mathrm{g} / \mathrm{ml}$ fungizone. The identity of RPE cells was confirmed by presence of melanin in primary cultures, autofluorescence, cytokeratin immunoreactivity, and cobblestone-like appearance at confluence. Bovine primary cultures were not suitable for stable transfection; therefore, the human D407 cell line (Dr Richard Hunt, University of South Carolina) was used. D407 cells were maintained in DMEM (Invitrogen Ltd, Renfrewshire, UK)

Abbreviations: $A G E$, advanced glycation endproduct; $A M D$, age related macular degeneration; CSLM, confocal scanning laser miscroscope; PBS, phosphate buffered saline; RPE, retinal pigment epithelium 
with $2 \%$ foetal calf serum, supplemented with glucose (20 mM).

\section{Preparation of advanced glycation endproducts and AGE-R antibodies}

Glucose derived AGE modification of bovine serum albumin (AGE albumin) was prepared as previously described. ${ }^{21}$ Briefly, BSA (Fraction V; Sigma-Aldrich Ltd, Dorset, UK) was incubated with $0.5 \mathrm{M}$ D-glucose in $0.2 \mathrm{M}$ phosphate buffered saline (PBS) at $37^{\circ} \mathrm{C}$ for 8 weeks under sterile conditions. Low molecular weight reactants and glucose were removed by dialysis against PBS with $10 \mathrm{kDa}$ cut off tubing (Invitrogen). The resulting AGE-BSA was then passed down an endotoxin binding affinity column (Pierce Inc, Rockford, IL, USA). Antisera against recombinant OST-48 (AGE-RI) has been previously described ${ }^{6}$ while the monoclonal antibody to $80 \mathrm{~K}-\mathrm{H}$ (AGE-R2) was obtained from Transduction Laboratories (Becton-Dickinson and Co, Franklin Lakes, NJ, USA). Rat monoclonal antibody to galectin-3 (AGE-R3) was collected from the tissue culture supernatants of the hybridoma M3/38 (American Type Culture Collection, Manassas, VA, USA).

\section{Real-time RT-PCR}

Total RNA was extracted from cells using Trizol reagent (Life Technologies) according to the manufacturer's instructions. The quantity and integrity of RNA was determined spectrophotometrically ( $280 \mathrm{~nm}$ and $260 \mathrm{~nm}$ ) and by visualisation of $18 \mathrm{~S}$ and $28 \mathrm{~S}$ rRNA bands after electrophoresis and staining with ethidium bromide.

RNA samples were reverse transcribed into cDNA using the 1st Strand cDNA Synthesis Kit (Roche Diagnostics Ltd, East Sussex, UK) as per manufacturer's instructions. All reactions were conducted in a thermal gene cycler (Bio-Rad Ltd, Richmond, CA, USA). As a negative control, the reverse transcriptase was omitted from one reaction mixture per RT reaction. The cDNA was used as a template for amplification in a polymerase chain reaction (PCR) using sequence-specific primers (Invitrogen) for AGE-R1, -R2, galectin-3, VEGF, and $28 \mathrm{~S}$ ribosomal RNA. The cDNA sequence of the primers and length of predicted products are shown in table 1.

cDNA samples were diluted $1 / 10$ and all reactions performed in triplicate. The cDNA $(2 \mu \mathrm{l})$ was mixed with $0.5 \mu \mathrm{M}$ sequence-specific primers, $4 \mathrm{mM} \quad \mathrm{MgCl}_{2}$, and Lightcycler Master mix (BioGene Ltd, Cambridgeshire, UK), to a final volume of $20 \mu$ l. The PCR reaction was performed in the Lightcycler (Roche Diagnostics Ltd, Lewes, UK) with an initial denaturation step at $95^{\circ} \mathrm{C}$ for 30 seconds, followed by 40 PCR cycles of denaturation at $95^{\circ} \mathrm{C}$, then a primer dependent annealing temperature for 3-5 seconds followed by elongation at $72^{\circ} \mathrm{C}$ for $4-9$ seconds. The elongation period was determined by product length, with a 1 second incubation for every $25 \mathrm{bp}$ of product. Fluorescence was measured once per cycle after the product extension phase. For negative

\begin{tabular}{llll}
\hline Table 1 & \multicolumn{2}{l}{ Primer sequences $\left(5^{\prime} 3^{\prime}\right)$} & \\
\hline mRNA & Forward primer & Reverse primer & Product \\
\hline AGE-R1 & AGGAGTACAGGT- & TCCCTITGATGG- & 177bp \\
& GCGTGTAG & CGATGAC & \\
AGE-R2 & TATGATGAGCA- & TGTACAGGTAGG- & 163bp \\
& GACGCAGG & CGAACTC & \\
Galectin-3 & GITGCCTTCCAC- & CATTCACTGCAACC- & $181 \mathrm{bp}$ \\
& TTAACCC & TTGAAG & \\
& TIGAAATCCGG- & ACATTGTCCAACA- & $100 \mathrm{bp}$ \\
VEGF & GGGAGAG & TGCCAG & \\
& CGAAACCATGAA- & CCTCAGTGGGCACA- 302bp \\
& CTTCTGC & CACTCC & \\
\hline
\end{tabular}

controls, one reaction was set up with cDNA absent from the reaction mixture and a second negative control consisted of a cDNA sample that had undergone the RT reaction, but had the RT omitted. In each series of PCR reactions, the standards used were dilutions of one of the samples (1:10, 1:20, 1:50, $1: 100)$.

Product melting curves were obtained immediately after the reaction by cooling the sample to $62^{\circ} \mathrm{C}$, then increasing the temperature slowly $\left(1^{\circ} \mathrm{C}\right.$ per second) to $95^{\circ} \mathrm{C}$ while monitoring the fluorescence continually. To verify the specificity of the melt curve analysis, PCR products were electrophoresed, stained with ethidium bromide $(10 \mu \mathrm{g} / \mathrm{ml})$, and visualised on a TFX-20M UV Transilluminator (Gibco) connected to a digital camera (Kodak Digital Science, Rochester, NY, USA).

\section{Immunocytochemistry}

RPE cells were cultured on four chamber microscope slides (Falcon, Becton-Dickinson) and exposed to AGE albumin in culture medium $(50,100$, and $200 \mu \mathrm{g} / \mathrm{ml})$. Cells were washed with PBS and fixed in $4 \%$ paraformaldehyde at room temperature for 10 minutes. The cells were then permeabilised by incubation with PBS containing $0.1 \%$ Triton-X followed by incubation with 5\% normal goat serum for 20 minutes at room temperature. The slides were then incubated with primary antibody (either anti-AGE-R1 (1:100), -R2 (1:100), galectin-3 (1:50)) for one hour at room temperature, washed and incubated with the appropriate Alexa fluor-488 conjugated secondary antibody (Molecular Probes Inc, Eugene, OR, USA) for one hour at room temperature. Cell nuclei were stained with $5 \mu \mathrm{g} / \mathrm{ml}$ propidium iodide (PI) and RNase A (Sigma) ( $1.6 \mu \mathrm{l}$ per $\mathrm{ml}$ in distilled water), for 20 minutes at room temperature. Slides were mounted in Vectashield (Vector Laboratories, Inc, Burlingame, CA, USA) and examined using a Bio-Rad Microradiance confocal scanning laser microscope (CSLM). Slides where the primary or secondary antibody was omitted acted as controls.

For identification of the lysosomal compartment, the LysoSensor Green DND-189 probe (Molecular Probes Inc) was used. This probe is fluorescent within acidic intracellular compartments and is selectively concentrated in acidic organelles as a result of protonation and in the low $\mathrm{pH}$ environment of lysosomes. The probe was added to the cells at a concentration of $1 \mu \mathrm{M}$ for one hour. The cells were then washed in PBS, mounted, and viewed using CSLM.

\section{Stable transfection of RPE}

The galectin-3 cDNA clone was obtained as a kind gift from A Raz (Mount Sinai Medical School, New York, USA). The cDNA was then cloned into EcoRI site of the pUNI/V5-His A vector (Invitrogen, CA, USA), it was then subcloned into BglII/BamHI sites of the pEGFP-Cl vector (Clontech, CA, USA). The Echo cloning system (Invitrogen) was then used to generate constructs for the over expression of the galectin3 GFP fusion protein. The donor vector (containing galectin-3 GFP cDNA) was created by subcloning the cDNA into the pUNI/V5-His B vector. The final pCMVgalectin-3 construct was then generated using recombinase enzyme to clone the galectin-3 cDNA into the pcDNA3.1E acceptor vector (with CMV promoter). A vector containing a pre-pro endothelin- 1 (PPET-1) promoter was also created. The PPET-1 promoter has been shown to direct endothelial specific gene expression and therefore acted as a negative control for transfected RPE.

Purified high quality plasmid DNA was obtained (Qiagen plasmid purification kit) and used to transfect cells using Effectene reagent (Qiagen, West Sussex, UK) according to the manufacturer's instructions. Cells were seeded at a density of $2.5 \times 10^{5}$ cells per well in a six well plate the day 

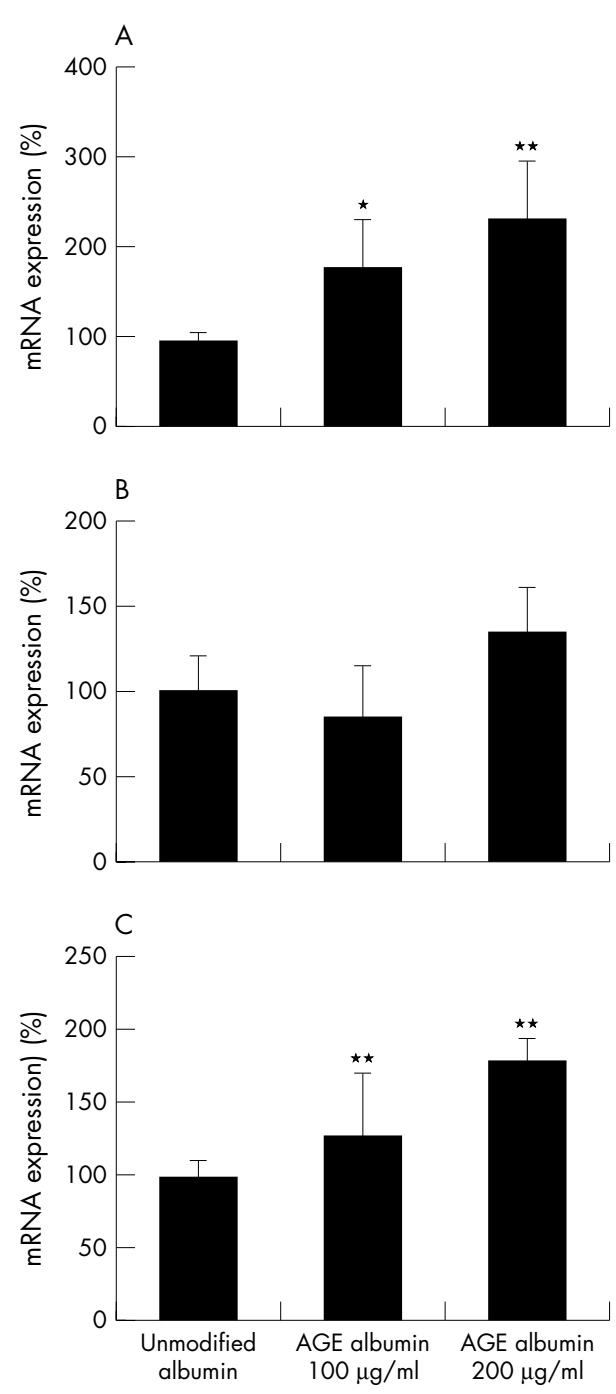

Figure 1 AGE receptor complex mRNA expression in RPE. For each of the receptor complex components, AGE-R1 (A), -R2 (B), galectin-3 (C) mRNA was measured by real-time RT-PCR after 4 days exposure to AGE. Treatment 1: control unmodified albumin. Treatment 2: $200 \mu \mathrm{g} / \mathrm{ml}$ AGE modified albumin. Treatment 3: $400 \mu \mathrm{g} / \mathrm{ml}$ AGE modified albumin. Values for control were set to $100 \%$ Each column represents the mean of three reactions normalised for $28 \mathrm{~S}$ rRNA levels. ${ }^{*} p<0.1$, ${ }^{* *} \mathrm{p}<0.05$.

before transfection, and were transfected with $0.4 \mu \mathrm{g}$ DNA using a DNA to Effectene ratio of 1:25. Cells were transfected with pCMV/GFP-galectin-3 and as a control cells were transfected with vector lacking the galectin-3 insert. Two days after transfection, stably transfected cells were selected

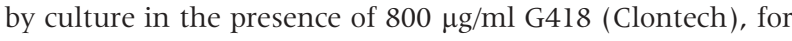
2 weeks, after which time control untransfected cells had died and resistant colonies had appeared. G418 resistant cells were then single cell cloned using cloning disks ( Sigma). The transfectants were then expanded in media supplemented

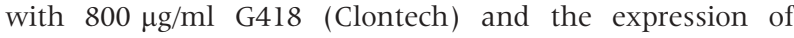
galectin-3 was assessed by western blotting and ELISA.

For western analysis, cell extracts were prepared as previously described $^{8}$ and protein concentrations estimated using a BCA protein concentration assay (Pierce, Rockford, IL, USA). Protein samples $(10 \mu \mathrm{g})$ were electrophoresed then transferred to Immobilon-P PVDF membrane (Millipore Ltd, Watford, UK). Non-specific binding was blocked with $4 \%$ dried milk and the membrane incubated with the appropriate primary antibody for one hour at room temperature. The membrane was then washed with PBS containing $0.1 \%$ Tween-20 followed by incubation for one hour with the appropriate horseradish peroxidase (HRP) conjugated secondary antibody (Dako Ltd, Glostrup, Denmark). Immunoreactivity was detected using enhanced chemiluminesence (Amersham, Little Chalfont, UK) exposed to Hyperfilm film (Amersham).

For ELISA, normal and transfected D407 cells were exposed to AGE albumin at varying concentrations to investigate variation in the secretion of the galectin-3 protein. After 4 days of exposure to AGE albumin, cell culture supernatants were isolated, spun to remove any residual non-adherent cells, and frozen until analysis. The ELISA assay was performed as per manufacturer's instructions (Caltag, Bender Medsystems, Northants, UK). Results were read immediately on a Tecan SAFIRE spectrophotometer (450 nm primary wavelength). All samples were run in duplicate microwell strips and a standard curve calculated for each run. Results were therefore expressed as means of three assay runs in duplicate. Statistical analysis (one-way ANOVA) was performed using the SPSS statistical software package (SPSS Inc, Chicago, IL, USA).

\section{RESULTS}

Real time PCR of AGE receptor components showed that all mRNAs were expressed in RPE. Exposure to AGE albumin caused a significant increase in AGE-Rl and galectin-3 mRNA levels while AGE-R2 did not alter expression (fig 1). CSLM revealed a distinct immunolocalisation pattern for the AGE receptor complex in RPE cells. AGE-R1, R2, and galectin-3 showed granular staining patterns (fig 2A-C). This pattern remained unaltered by AGE treatment ( 100 or $200 \mu \mathrm{g} / \mathrm{ml}$ ) (data not shown). The Lysosensor probe demonstrated the particulate staining pattern typical of the low $\mathrm{pH}$ cytoplasmic compartments (fig 2D). For all receptor components, this pattern showed a similar lysosomal-like distribution in RPE cells as revealed by the distinctive, punctate vesicular immunofluorescent pattern, often occurring in the perinuclear regions of the cytoplasm (compare fig 2A-C with 2D). Galectin-3 demonstrated some diffuse cytoplasmic and plasma membrane associated immunoreactivity. Immunofluorescence and Lysosensor probe controls showed no significant fluorescence (data not shown).
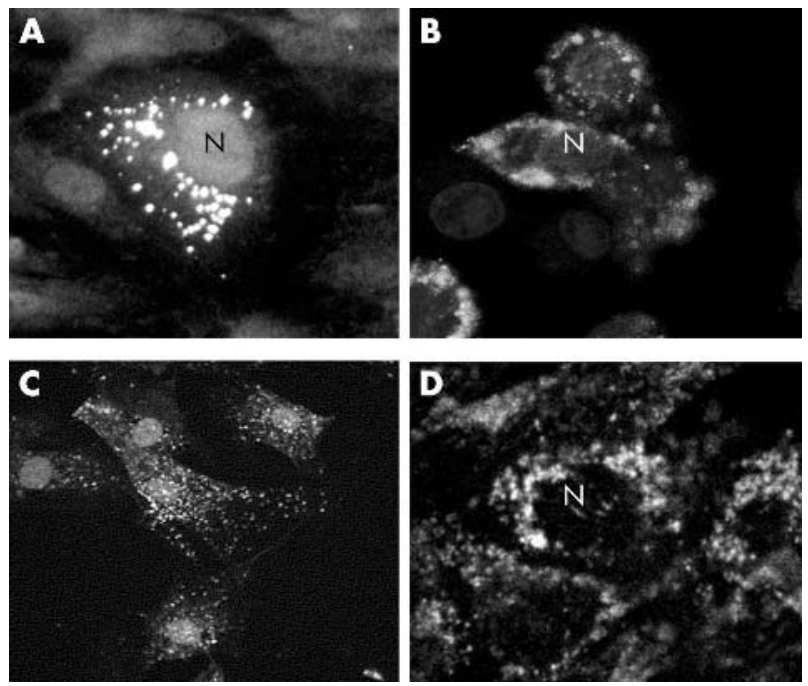

Figure 2 AGE receptor immunolocalisation and low pH compartments in RPE cells. Confocal scanning laser microscopy was conducted for each of the component proteins AGE-R1 (A), AGE-R2 (B), galectin-3 (C). All three components show granular staining patterns (fig 2A-C). Treatment with the lysosensor probe revealed a distinctive particulate, perinuclear staining pattern (D). Original magnification $\times 200$. 
D407 cells transfected with pCMV GFP exhibited strong expression of GFP in the nucleus and cytoplasm (fig 3A-D). D407 cells were also transfected with 3.1 PPET-1 GFP as a negative control, as the PPET-1 promoter is known to direct endothelial specific gene expression. As expected there was a low expression level of GFP (results not shown). Expression of galectin-3 in all transfected clones was confirmed by western analysis of whole cell lysates. Blots were probed with antigalectin-3 antibody to assess protein expression levels in stably transfected cells (fig 3E). It was found that clones 3 and 4 expressed higher levels of galectin-3 in comparison with control transfected cells (clone 6; fig 3E). Therefore, galectin-3 clone 3 and control clone 6 were used in all subsequent experiments.

AGEs are known to upregulate VEGF mRNA expression in RPE cells. ${ }^{13}$ To further investigate the role of the galectin-3 AGE receptor component in mediating this response, VEGF mRNA levels were quantified in "wild type" and RPE cells overexpressing galectin-3 following AGE exposure. Control cells showed a significant increase in VEGF mRNA levels after AGE exposure $(p<0.05)$. In contrast, cells expressing high levels of galectin-3 did not have increased VEGF mRNA after AGE exposure (fig 4).

ELISA analysis of culture medium from RPE revealed that soluble galectin-3 was released by these cells. In wild type, non-transfected cells, there was a marked reduction of galectin-3 release into the medium $(\mathrm{p}<0.05)$ when exposed to AGE albumin (fig 5). This response was concentration dependant. By contrast, the transfected RPE released less AGE-R3 into the medium than the control cells, and there was a markedly different response of these cells to AGE exposure. These cells increased galectin-3 release upon treatment with AGE albumin $(\mathrm{p}<0.01)$, a response that was maintained throughout the concentration range (fig 5 ).
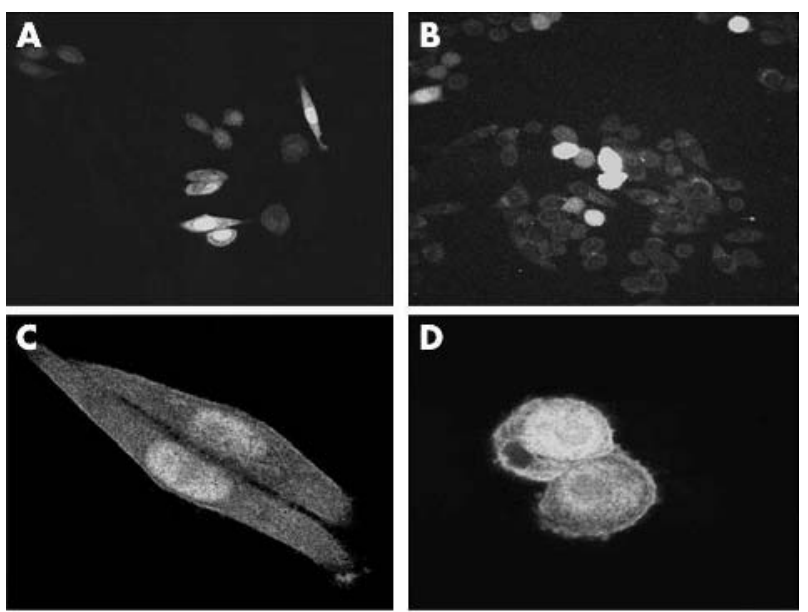

$\mathbf{E}$

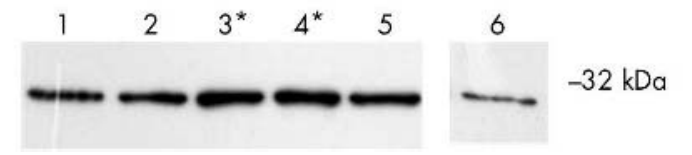

Figure 3 Transfection of RPE with galectin-3. GFP expression was used to assess transfection efficiency. Panels A-D show RPE cells from different transfection experiments exposed to pCMV-GFP. In both colonies, GFP expression occurs in a high proportion of cells and at high magnification is detected strongly in the nucleus but also in the perinuclear region and cyłoplasm of cells 24 hours after transfection. Original magnification $\times 200(A, B) ; \times 400$ (C, D). (E) Western analysis demonstrates galectin-3 expression in transfectants, with lanes $3^{*}$ and $4^{*}$ (selected clones) expressing higher levels of galectin-3 in comparison with control transfected cells (lane 6).

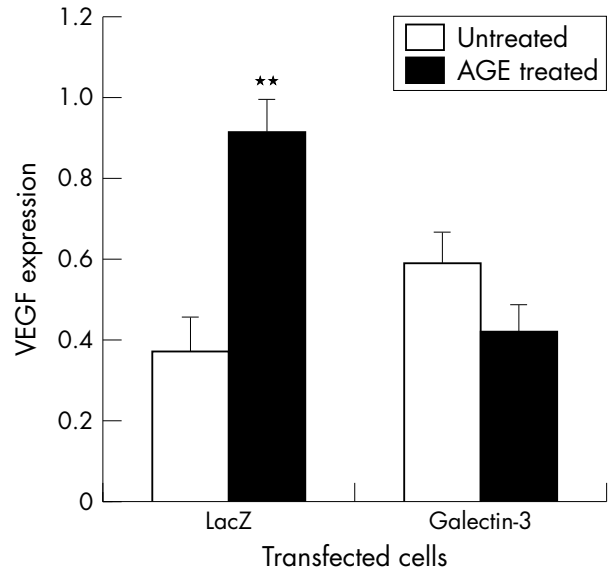

Figure 4 AGEs increase VEGF expression in RPE, an effect reversed by overexpression of galectin-3. VEGF mRNA was quantified by real time RT-PCR after exposure of control or transfected RPE to AGE modified albumin $(200 \mu \mathrm{g} / \mathrm{ml})$. There is a significant increase in VEGF expression after treatment with AGEs $(p<0.05)$, whereas this response is completely lost in the galectin- 3 transfectants. Each column represents the mean of $n=3$ experiments with reactions normalised for $28 S$ mRNA.

\section{DISCUSSION}

Advanced glycation endproduct receptors are highly conserved and have been characterised in many different cell types other than RPE. ${ }^{618} 22$ This study demonstrates for the first time that the components of the AGE receptor complex are present within the RPE and are, at least in part, plasma membrane and lysosome associated. Although this study has not investigated other AGE receptor proteins, such as RAGE, there is evidence to suggest that the galectin-3 component modulates some AGE mediated responses in RPE and may make a contribution to age related pathology.

In response to soluble AGE exposure, expression of the AGE-Rl and galectin-3 components were significantly upregulated at a transcriptional level in a concentration dependent manner. This differs slightly from the response observed

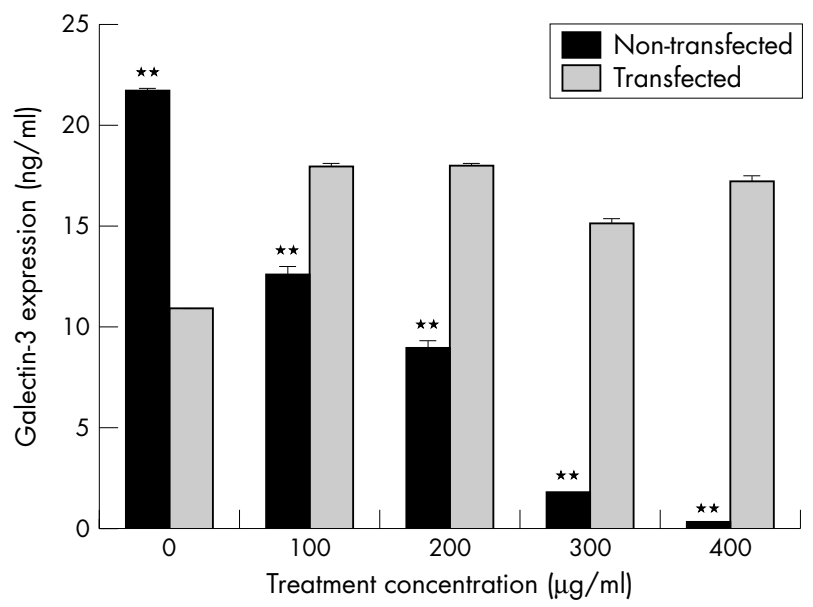

Figure 5 Soluble galectin-3 is released by RPE. Levels of soluble galectin- 3 were measured by ELISA after 4 days exposure to soluble AGEs and demonstrated that this protein is released by RPE. Nontransfected cells exposed to increasing concentrations of AGE albumin show a significant reduction of galectin-3 release into the medium $\left({ }^{* *} p<0.05\right)$. In the transfectants, there is less soluble galectin-3 in comparison to controls (** $\mathrm{p}<0.05$ ) but upon exposure to AGEs, this protein was increased over non-modified albumin controls - a response maintained throughout the concentration range. 
in other cell types such as endothelial cells and blood borne monocytes ${ }^{8}$ and this may reflect the very different roles of RPE cells in vivo. The impact that such a regulatory mechanism may have on RPE function is unknown, although it may represent a response by the cells to limit AGE uptake under conditions of chronic exposure from blood borne AGE modified lipids and proteins, either from the choriocapillaris or photoreceptor outer segments. Alternatively, upregulation could be associated with increased cellular activation of pathophysiological pathways, including growth factor upregulation. AGE-R expression or function may also be subject to gene related modulation, which in turn may influence tissue specific gene functions. ${ }^{23}$ Altered expression and activity of the AGE-Rl component has also recently been found in humans with diabetic complications ${ }^{24}$ where AGE levels are typically increased, suggesting a genetic basis for altered expression. Several gene polymorphisms have been detected in most AGE-R components, but no significant correlation to diabetic complications or age related pathology has as yet been found. ${ }^{25}$

Various studies have shown that AGE receptor binding mediates important cell specific responses, such as enhanced synthesis of extracellular matrix molecules ${ }^{26}$ increased expression of different growth factors and cytokines, ${ }^{11}{ }^{18}$ AGE accumulation in lysosomes, and inappropriate vasopermeability responses. ${ }^{9}{ }^{10}$ The existence of AGE receptor proteins in the RPE and their response to AGE ligands indicates that these proteins could have a role in binding, endocytosing, and degrading AGE modified proteins. If such a process occurs in vivo, it could serve to remove AGE modified molecules from the ocular circulation in vivo thereby preventing their accumulation extracellularly in Bruch's membrane. It remains to be determined whether AGE receptor proteins could be abnormal or subject to downregulation under certain pathological conditions of the RPE or with ageing.

Although it is likely that AGE receptors in the RPE are responsible for the binding, uptake, and degradation of AGE modified molecules, it remains unclear exactly what trafficking mechanisms are present in actively phagocytic RPE cells. It has been shown that epithelial cells of renal glomeruli ${ }^{27}$ and retinal microvascular endothelial cells phagocytose and transport AGEs to the lysosomal compartment. ${ }^{9}$ Receptor mediated transport of reactive moieties to the lysosomal compartment of RPE may have a significant impact on proteolysis and protease activity, perhaps leading to lipofuscin accumulation ${ }^{28}$ and this is the subject of ongoing investigation.

The importance of galectin-3 as an AGE receptor has been previously demonstrated ${ }^{101129}$ and the current study indicates that this protein could play a role in AGE mediated RPE dysfunction. Pugliese et al have demonstrated that galectin-3 may show a contrasting regulatory response to RAGE when renal cells are exposed to AGEs, ${ }^{29}{ }^{30}$ indicating that galectin-3 could be protective against AGE mediated pathological responses. Galectin-3 has been only relatively recently described as a putative AGE receptor and it is well established that this protein has many roles in cell adhesion, inflammatory responses, cell differentiation, and chemoattraction. ${ }^{31}$ It remains possible that overexpression of galectin-3 could possibly exert effects on RPE that are additional to or distinct from AGE binding.

In order to establish the role of galectin-3 in mediating AGE effects on RPE this protein was stably expressed into a well characterised human RPE cell line. A known effect of AGEs on the RPE is to upregulate VEGF mRNA expression ${ }^{13}$ and the current study has further confirmed this response. VEGF mRNA levels were also measured in galectin-3 transfected cells following AGE exposure, where it was found that expression levels decreased in contrast to non-transfected controls. Thus it appears that instead of increasing cell activation by AGEs, overexpression of galectin-3 component may serve to protect against the effects of AGEs on the RPE. Galectin-3 is known to be secreted by cells into the extracellular space ${ }^{32}$ so the current study sought to determine if AGE exposed cells secrete this protein into the culture medium. As revealed by ELISA, AGEs actually reduce galectin-3 secretion into the medium, although this response is lost in transfected cells. The immunolocalisation studies suggested that galectin-3 occurs on the plasma membrane and within intracellular compartments. It is possible that when galectin-3 is released into the medium it may serve to bind soluble AGE proteins and perhaps limit their interaction with the range of AGE receptors on the cell surface. This phenomenon requires further investigation.

\section{ACKNOWLEDGEMENTS}

This research is supported by The Wellcome Trust and by The Iris Fund (UK). The authors would like to thank Dr Richard Hunt (University of South Carolina) for the generous gift of the human D407 cell line and Professor Helen Vlassara (Mount Sinai Medical School, New York) for donation of AGE-Rl antibodies.

\section{Authors' affiliations}

S McFarlane, J V Glenn, A M Lichanska, D A C Simpson, A W Stitt, Queen's University of Belfast, Institute of Clinical Science, Royal Victoria Hospital, Belfast, UK

\section{REFERENCES}

1 Boulton M, Dayhaw-Barker P. The role of the retinal pigment epithelium: topographical variation and ageing changes. Eye 2001;15:384-9.

2 Hageman GS, Luthert PJ, Victor Chong NH, et al. An integrated hypothesis that considers drusen as biomarkers of immune-mediated processes at the RPE-Bruch's membrane interface in aging and age-related macular degeneration. Prog Retin Eye Res 2001;20:705-32.

3 Baynes JW. The role of AGEs in aging: causation or correlation. Exp Gerontol 2001;36:1527-37.

4 Thornalley PJ. Cell activation by glycated proteins. AGE receptors, receptor recognition factors and functional classification of AGEs. Cell Mol Biol (Noisyle-grand) 1998;44:1013-23.

5 Schmidt AM, Yan SD, Yan SF, et al. The biology of the receptor for advanced glycation end products and its ligands. Biochim Biophys Acta 2000; 1498:99-111.

6 Li YM, Mitsuhashi T, Wojciechowicz D, et al. Molecular identity and cellular distribution of advanced glycation endproduct receptors: relationship of p60 to OST-48 and $\mathrm{p} 90$ to $80 \mathrm{~K}-\mathrm{H}$ membrane proteins. Proc Natl Acad Sci U S A 1996;93:1 1047-52.

7 Vlassara H, Li YM, Imani F, et al. Identification of galectin-3 as a high-affinity binding protein for advanced glycation end products (AGE): a new member of the AGE-receptor complex. Mol Med 1995;1:634-46.

8 Stitt AW, He C, Vlassara H. Characterization of the advanced glycation endproduct receptor complex in human vascular endothelial cells. Biochem Biophys Res Commun 1999;256:549-56.

9 Stitt AW, Burke GA, Chen F, et al. Advanced glycation end-product receptor interactions on microvascular cells occur within caveolin-rich membrane domains. Faseb J 2000;14:2390-2.

10 Zhu W, Sano H, Nagai R, et al. The role of galectin-3 in endocytosis of advanced glycation end products and modified low density lipoproteins. Biochem Biophys Res Commun 2001;280:1183-8.

11 Seki N, Hashimoto N, Sano H, et al. Mechanisms involved in the stimulatory effect of advanced glycation end products on growth of rat aortic smooth muscle cells. Metabolism 2003;52:1558-63.

12 Handa JT, Reiser KM, Matsunaga $\mathrm{H}$, et al. The advanced glycation endproduct pentosidine induces the expression of PDGF-B in human retinal pigment epithelial cells. Exp Eye Res 1998;66:411-19.

13 Lu M, Kuroki M, Amano S, et al. Advanced glycation end products increase retinal vascular endothelial growth factor expression. J Clin Invest 1998;101:1219-24.

14 Esposito C, Gerlach H, Brett J, et al. Endothelial receptor-mediated binding of glucose-modified albumin is associated with increased monolayer permeability and modulation of cell surface coagulant properties. J Exp Med 1989; 170: 1387-407.

15 Vlassara H, Brownlee M, Cerami A. Novel macrophage receptor for glucosemodified proteins is distinct from previously described scavenger receptors. $J$ Exp Med 1986;164:1301-9.

16 Abel M, Ritthaler U, Zhang Y, et al. Expression of receptors for advanced glycosylated end-products in renal disease. Nephrol Dial Transplant 1995; 10:1662-7.

17 Sano H, Nagai R, Matsumoto K, et al. Receptors for proteins modified by advanced glycation endproducts (AGE) - their functional role in atherosclerosis. Mech Ageing Dev 1999;107:333-46. 
18 Li JJ, Dickson D, Hof PR, et al. Receptors for advanced glycosylation endproducts in human brain: role in brain homeostasis. Mol Med 1998;4:46-60.

19 Festa A, Schmolzer B, Schernthaner G, et al. Differential expression of receptors for advanced glycation end products on monocytes in patients with IDDM. Diabetologia 1998;41:674-80.

20 Patton WP, Chakravarthy U, Davies RJ, et al. Comet assay of UV-induced DNA damage in retinal pigment epithelial cells. Invest Ophthalmol Vis Sc 1999:40:3268-75

21 Stitt AW, Li YM, Gardiner TA, et al. Advanced glycation end products (AGEs) co-localize with AGE receptors in the retinal vasculature of diabetic and of AGE-infused rats. Am J Pathol 1997; 150:523-31.

22 Pugliese G, Pricci F, Leto $G$, et al. The diabetic milieu modulates the advanced glycation end product-receptor complex in the mesangium by inducing or upregulating galectin-3 expression. Diabetes 2000:49:1249-57.

23 Vlassara $\mathbf{H}$. The AGE-receptor in the pathogenesis of diabetic complications. Diabetes Metab Res Rev 2001;17:436-43.

$24 \mathrm{He} \mathrm{CJ}$, Koschinsky T, Buenting C, et al. Presence of diabetic complications in type 1 diabetic patients correlates with low expression of mononuclear cell AGE-receptor-1 and elevated serum AGE. Mol Med 2001;7:159-68.
25 Poirier O, Nicaud V, Vionnet N, et al. Polymorphism screening of four genes encoding advanced glycation end-product putative receptors. Association study with nephropathy in type 1 diabetic patients. Diabetes 2001:50:1214-18.

26 Pugliese G, Pricci F, Romeo G, et al. Upregulation of mesangial growth factor and extracellular matrix synthesis by advanced glycation end products via a receptor-mediated mechanism. Diabetes 1997;46:1881-7.

27 Gugliucci A, Bendayan M. Renal fate of circulating advanced glycated end products (AGE): evidence for reabsorption and catabolism of AGE-peptides by renal proximal tubular cells. Diabetologia 1996:39:149-60.

28 Kennedy CJ, Rakoczy PE, Constable IJ. Lipofuscin of the retinal pigment epithelium: a review. Eye 1995;9:763-71

29 Pugliese G, Pricci F, lacobini C, et al. Accelerated diabetic glomerulopathy in galectin-3/AGE receptor 3 knockout mice. Faseb J 2001;15:2471-9.

30 lacobini C Amadio L, Oddi G, et al. Role of galectin-3 in diabetic nephropathy. J Am Soc Nephrol 2003;14(Suppl 3):S264-70.

31 Yang RY, Liu FT. Galectins in cell growth and apoptosis. Cell Mol Life Sci 2003;60:267-76

32 Menon RP, Hughes RC. Determinants in the $\mathrm{N}$-terminal domains of galectin-3 for secretion by a novel pathway circumventing the endoplasmic reticulumGolgi complex. Eur J Biochem 1999;264:569-76.

\section{Clinical Evidence-Call for contributors}

Clinical Evidence is a regularly updated evidence-based journal available worldwide both as a paper version and on the internet. Clinical Evidence needs to recruit a number of new contributors. Contributors are healthcare professionals or epidemiologists with experience in evidence-based medicine and the ability to write in a concise and structured way.

Areas for which we are currently seeking authors:

- Child health: nocturnal enuresis

- Eye disorders: bacterial conjunctivitis

- Male health: prostate cancer (metastatic)

- Women's health: pre-menstrual syndrome; pyelonephritis in non-pregnant women However, we are always looking for others, so do not let this list discourage you.

Being a contributor involves:

- Selecting from a validated, screened search (performed by in-house Information Specialists) epidemiologically sound studies for inclusion.

- Documenting your decisions about which studies to include on an inclusion and exclusion form, which we keep on file.

- Writing the text to a highly structured template (about 1500-3000 words), using evidence from the final studies chosen, within 8-10 weeks of receiving the literature search.

- Working with Clinical Evidence editors to ensure that the final text meets epidemiological and style standards.

- Updating the text every six months using any new, sound evidence that becomes available. The Clinical Evidence in-house team will conduct the searches for contributors; your task is simply to filter out high quality studies and incorporate them in the existing text.

- To expand the topic to include a new question about once every 12-18 months.

If you would like to become a contributor for Clinical Evidence or require more information about what this involves please send your contact details and a copy of your CV, clearly stating the clinical area you are interested in, to Klara Brunnhuber (kbrunnhuber@ bmigroup.com).

\section{Call for peer reviewers}

Clinical Evidence also needs to recruit a number of new peer reviewers specifically with an interest in the clinical areas stated above, and also others related to general practice. Peer reviewers are healthcare professionals or epidemiologists with experience in evidence-based medicine. As a peer reviewer you would be asked for your views on the clinical relevance, validity, and accessibility of specific topics within the journal, and their usefulness to the intended audience (international generalists and healthcare professionals, possibly with limited statistical knowledge). Topics are usually 1500-3000 words in length and we would ask you to review between 2-5 topics per year. The peer review process takes place throughout the year, and our turnaround time for each review is ideally 10-14 days.

If you are interested in becoming a peer reviewer for Clinical Evidence, please complete the peer review questionnaire at www.clinicalevidence.com or contact Klara Brunnhuber (kbrunnhuber@bmigroup.com). 